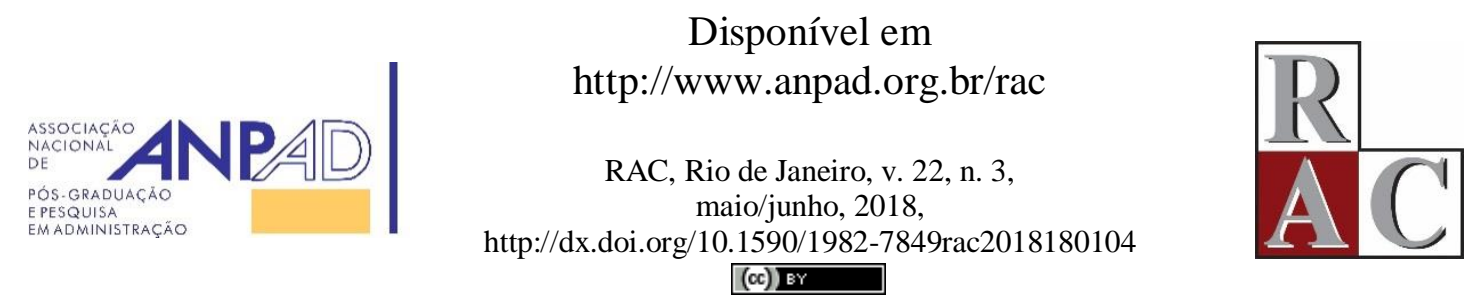

\title{
Editorial:
}

\section{O Aprendizado em Editoração Científica}

Herbert Kimura

Universidade de Brasília, Brasília, DF, Brasil

Editor-chefe da RAC

Apresentamos a nova edição da Revista de Administração Contemporânea (RAC), sendo esta minha última contribuição como editor-chefe, posição que ocupo desde janeiro de 2012.

Foram mais de seis anos de muito trabalho, sacrifício e renúncia, com alguns momentos de satisfação, derivada tanto na publicação de edições com trabalhos de impacto na comunidade acadêmica quanto no aprendizado do processo editorial de um importante periódico científico.

A publicação das edições da RAC envolve um trabalho árduo que depende da coordenação de autores, avaliadores, editores, equipe editorial e outros colaboradores. A qualidade de um artigo publicado é fruto de uma submissão pelos autores de matéria-prima de alto nível, de uma análise rigorosa por editores e avaliadores, que implica em aperfeiçoamentos no trabalho, e de um processo cuidadoso de editoração, que envolve ajustes na formatação, na redação, e nas referências. Assim, cada edição publicada traz uma satisfação que reflete o esforço conjugado de vários atores para um objetivo comum.

O aprendizado adquirido na editoração de uma revista influente e de grande exposição na comunidade é outro motivo de satisfação. A pressão decorrente da responsabilidade como editor implica na busca por conhecimento que não é usual a um pesquisador que tipicamente navega entre os papéis de autor ou de avaliador. Além de aspectos de coordenação de equipes, planejamento de processos e gestão de conflitos, elementos técnicos de editoração são também importantes.

Neste contexto, foi promovido, ao longo desses anos, um investimento substancial para a capacitação da equipe editorial. Tendo em vista as fortes mudanças no segmento de editoração científica, faz-se necessária uma constante atualização, tanto em relação à adoção de tecnologias quanto à imposição de novas regras de conduta e de procedimentos.

Tendo participado de diversos programas de capacitação, como, por exemplo, Associação Brasileira de Editores Científicos (ABEC) e SciELO, e tendo sido o primeiro editor brasileiro certificado pelo Council of Science Editors (CSE), tive contato com novas perspectivas de editoração e vislumbro 
grandes desafios em todas as áreas prioritárias indicadas pelo SciELO, notadamente envolvendo a necessidade de profissionalização do segmento, a superação das dificuldades para sustentabilidade financeira e o incentivo à internacionalização dos periódicos (Packer, 2014, 2016).

Diversos avanços foram obtidos durante esses anos. As métricas de desempenho como, por exemplo, as disponibilizadas pelo SciELO e pelo SPELL, e as frequentes conquistas em editais de apoio à publicação de periódicos científicos mostram a relevância e a influência da RAC. Pesquisadores podem levantar as várias métricas e conferir a posição de liderança da RAC na comunidade científica.

A despeito das conquistas, existem também os desafios para o periódico como, por exemplo, um maior comprometimento de pareceristas com o processo editorial (Kimura, 2016a, 2016b), além de uma maior internacionalização do periódico, com uma exposição maior em fóruns internacionais e listagem em outros indexadores. Esses desafios deverão ser analisados tanto pela nova equipe editorial quanto pela nova diretoria da ANPAD.

Focando nos artigos desta edição, apresentamos 6 Artigos Científicos e 1 Artigo Tecnológico, que exploram diversas perspectivas e abordagens em Administração.

No primeiro artigo científico, Sobrevivência de Empresas Nascentes: Influência do Capital Humano, Social, Práticas Gerenciais e Gênero, Mariana Bertolami, Rinaldo Artes, Pedro João Gonçalves, Marcos Hashimoto e Sergio Giovanetti Lazzarini, analisam "a influência do capital humano do empreendedor, o seu capital social e a adoção de práticas gerenciais na sobrevivência de empresas em seus primeiros anos de atividade". O estudo indica "que empreendedoras enfrentam mais barreiras à constituição de novos negócios, exigindo, portanto, configurações distintas de recursos para atenuar essas barreiras e aumentar a probabilidade de sobrevivência das empresas nascentes".

Já o segundo artigo científico, Segmento de Tecnologia Analisado pela Multidimensional Work Motivation Scale, de Clarice Lucas da Silva Machado, Patrícia Martins Fagundes Cabral e Guilherme Luís Roehe Vaccaro, analisa "os fatores motivacionais através da Teoria da Autodeterminação ... e da aplicação da Multidimensional Work Motivation Scale (MWMS) ..., em trabalhadores de empresas de tecnologia do Sul do Brasil". Os resultados sugerem que "trabalhadores são primordialmente orientados pela Motivação Autônoma, seguidos pela Motivação Controlada".

O terceiro artigo científico, Fundos de Investimento: Performance aplicando Modelo Carhart e Análise Envoltória de Dados, de Simone Evangelista Fonseca, Anderson Rocha Fernandes, Cristiana Lara Cunha e Robert Aldo Iquiapaza, "avalia o desempenho de fundos de investimento brasileiros em ações, comparando retornos reais e indicadores paramétricos e não paramétricos de performance". Os resultados indicam uma "queda de performance dos fundos, apontada pela literatura, alta correlação dos alfas com os retornos reais, baixa correlação dos scores com retornos e mais baixa correlação entre alfas e scores".

No quarto artigo científico, Envolvimento Estratégico da Média Gerência: Analisando o Passado e Projetando o Futuro, Samir Lótfi Vaz e Sergio Bulgacov analisam "literatura que destaca o papel de indivíduos da média gerência na estratégia". O estudo apresenta categorias que "descrevem diferentes tipos de envolvimento da média gerência na estratégia, indicando maior diversidade de possíveis caminhos teóricos, metodológicos e contextuais sobre o tema".

O quinto artigo científico, O Uso de Biomarcadores em Pesquisas de Marketing, de Cristina Maria de Aguiar Pastore, Eliane Cristine Francisco Maffezzolli e José Afonso Mazzon, "apresenta e compara algumas ferramentas neurocientíficas que são fundamentadas em respostas não cognitivas do cérebro humano". Mais especificamente, a "metodologia de aplicação dessas ferramentas, medidas resultantes e possíveis interpretações de comportamento também são discutidas, com ênfase em futura agenda de pesquisa".

O sexto artigo científico, Sustainable Competitive Advantage Needs Green Human Resources Practices: A Framework to Environmental Management, de Lívia Almada e Renata Borges, investiga "o papel da gestão de recursos humanos $(\mathrm{RH})$ para alcançar a vantagem competitiva 
sustentável (VCS) nas organizações, por meio da perspectiva da Visão Baseada em Recursos Naturais (VBRN)". O trabalho busca agregar "valor aos gerentes, apresentando formas de implementar o gerenciamento de RH para a realização da sustentabilidade organizacional".

O artigo tecnológico desta edição, Concursos Públicos Docentes em uma Universidade Federal: Proposta de Melhorias em Software, de Matheus Boni Barbosa e Elvis Silveira-Martins, "propõe um plano de intervenção para a solução de dificuldades e de melhorias relativas ao processo de realização de provas em Concursos Públicos e Processos Seletivos em uma Universidade Federal". No estudo, discute-se "uma proposta de intervenção para atuar sobre as funcionalidades atuais do software, para se criarem novas funcionalidades e para promover a integração do software ao portfólio institucional, permitindo atuar eficazmente na correção e na prevenção de equívocos, bem como na melhoria dos processos".

Finalmente, agradeço a confiança depositada pela ANPAD, durante três diferentes mandatos de diretorias. Apesar de terem sido mais de seis anos de sacrifício, trabalho árduo, foram também de humilde aprendizado e de tentativas de realizar as atividades de acordo com o padrão que se exige de um periódico de ponta.

Despeço-me da RAC e dou as boas-vindas ao professor Wesley Mendes-da-Silva para a posição de editor-chefe do periódico.

\section{Referências}

Kimura, H. (Ed.). (2016a). Editorial. Revista de Administração Contemporânea, 20(1). Recuperado de http://anpad.org.br/periodicos/arq_pdf_edit/1_20_01.pdf. $\quad$ http://dx.doi.org/10.1590/19827849rac2016150328

Kimura, H. (Ed.). (2016b). Editorial. Revista de Administração Contemporânea, 20(2). Recuperado de http://www.scielo.br/pdf/rac/v20n2/1982-7849-rac-20-2-1982-7849rac2016160044.pdf. http://dx.doi.org/10.1590/1982-7849rac2016160044

Packer, A. (2014 junho 16). Os desafios da profissionalização. SciELO em Perspectiva [blog]. Recuperado em 28 abril, 2018, de https://blog.scielo.org/blog/2014/06/16/os-desafios-daprofissionalizacao/

Packer, A. (2016 dezembro 21). SciELO e o futuro dos periódicos. SciELO em Perspectiva [blog]. Recuperado em 28 abril, 2018, de https://blog.scielo.org/blog/2016/12/21/scielo-e-o-futuro-dosperiodicos/

\section{Dados do Autor}

Herbert Kimura

Prédio da FACE, Sala A1-82-7, Campus Universitário Darcy Ribeiro, 70910-900, Brasília, DF, Brasil. E-mail: rac.herbert.kimura@gmail.com. https://orcid.org/0000-0001-6772-1863 